\title{
O programa linguístico de Benveniste e a constituição da linguística textual proposta por Adam
}

\author{
Alena Ciulla ${ }^{1}$ \\ Programa de Pós-Graduação em Linguística, Universidade Federal do Rio Grande do Sul, Porto Alegre, RS, Brasil
}

Resumo: Diante das diversas perspectivas de estudos apresentadas sob a égide da linguística textual, faz-se necessário um posicionamento da parte de todo pesquisador que tenha o texto como objeto de análise. Neste artigo, investigamos os fundamentos da análise textual dos discursos, de Jean-Michel Adam. Retornando aos estudos que questionam os limites da ciência linguística, entre langue e a parole, que estão diretamente relacionados também à discussão do estatuto da frase, é em Benveniste que Adam encontra suporte para dar uma saída à questão. Situando o estudo do texto em uma linguística do discurso, Adam considera o texto como produto da enunciação e, portanto, na interdependência entre os domínios do semiótico e do semântico. Por fim, a partir da sugestão de um "novo aparelho de conceitos e definições", Adam propõe categorias próprias para o texto, subdividindo o texto em segmentos, da proposição-enunciada à sequência, e explicitando tipos de ligação entre unidades textuais.

Palavras-chave: Translinguística; Linguística textual; Enunciação; Análise textual dos discursos; História das ideias linguísticas.

Title: Benveniste's linguistic program and the constitution of the textual linguistics proposed by Adam Abstract: Given the different perspectives of studies presented under the aegis of the textual linguistics, it is necessary for every researcher, who intends to work the text as an analytical object, to take on a position. In this article, we investigate the foundations of the JeanMichel Adam's textual analysis of discourses. Bringing back the inquiry about the limits of the linguistics science, between langue and parole, which is also directly related to the discussion on the status of the sentence, it is in Benveniste that Adam finds support to a way out of that question. Adam places the study of the text in the field of a discourse linguistics, and defines the text as an act of enunciation, in the interdependency of the semiotic and semantic domains. Finally, from the suggestion of a "new apparatus of concepts and definitions", Adam propose specific categories for the text, subdividing the text, from the enunciated proposition to the sequence and outlining types of connection among textual unities.

Keywords: Translinguistics; Textual linguistics; Enunciation; Textual analysis of discourses; History of linguistics ideas.

\footnotetext{
${ }^{1}$ Professora do Departamento de Letras Clássicas e Vernáculas e do Programa de Pós-Graduação em Linguística, Instituto de Letras, Universidade Federal do Rio Grande do Sul (UFRGS), Brasil. Orcid: https://orcid.org/00000002-0710-9397. E-mail: alenacs@gmail.com.
} 


\section{Introdução}

Nosso trabalho é parte de um projeto de pesquisa de natureza explicativa sobre a referência, a partir de Benveniste, e sobre outros fenômenos de linguagem em que o estudo da referência pode estar implicado, como dêixis, anáfora, tradução e texto. Este artigo, em especial, faz parte do intuito de encontrar um lugar para o texto nos estudos linguísticos, a partir do programa benvenisteano de estudo da linguagem. Para tanto, como um primeiro passo da nossa reflexão, é apresentada, aqui, uma leitura de Émile Benveniste, feita por JeanMichel Adam, a partir da qual este último fundamenta sua proposta de abordagem da linguística textual.

A justificativa desta investigação apoia-se principalmente no fato de que, diante das diversas perspectivas de estudos apresentadas sob a égide da linguística textual, faz-se necessário um posicionamento da parte de todo pesquisador que tenha o texto como objeto ou unidade de análise.

Jean-Michel Adam tem uma vasta publicação na área, desde 1984, e continua publicando até hoje. Mas muito mais do que um produtor de quantidade, foi um dos precursores da linguística textual, sendo um dos primeiros a colocar em xeque as análises transfrásticas e as gramáticas de texto, com a publicação de Eléments de linguistique textuelle, em 1990.

As análises transfrásticas primavam por uma tendência de observar mecanismos entre as frases, considerando-os no que diz respeito ao alcance do sistema gramatical da língua. Assim, os estudos se concentravam principalmente nos recursos de coesão, isto é, nos elos coesivos que relacionam frases. $O$ conceito de coesão textual, para esses autores, englobava o de coerência, a qual, por sua vez, era considerada como propriedade do sistema da língua ao compor frases, e, a seguir, frases ordenadas em textos. O texto, para essas abordagens era, então, visto meramente como uma "frase complexa". Conforme veremos mais adiante, neste artigo, Adam, seguindo Benveniste, considera que a frase não se define apenas por seus constituintes, nem pode integrar uma unidade de hierarquia superior imediata, pois há, aí, um hiato, que indica que a língua comporta dois domínios diferentes. Então, se, de um lado, a gramática transfrástica pode ser considerada como uma extensão da linguística clássica, que tenta explicar e descrever o domínio do signo, de outro lado, para Adam, a linguística textual necessita de uma teoria que alcance o domínio da produção co(n)textual de sentido.

Sob a perspectiva de Adam (2016), que se junta a Charolles (1989) para desenvolver sua crítica, estudos de análises transfrásticas, como os de Ruwet (1975) e Bellert (1970) não davam conta de restrições globais que regem a articulação de frases, muito menos da articulação de sequências de enunciados que constituem os textos. Por isso, a necessidade de prever uma teoria do texto que dê conta da coerência sequencial (da microestrutura), e da coerência textual propriamente dita (ou macroestrutural).

Adam também se afasta dos modelos gerativistas de análise textual, em cuja proposta 
de reagrupamento de proposições, os princípios observados são menos linguísticos (no sentido estrito do termo) e mais cognitivos, pois dizem respeito aos limites e conhecimentos armazenados na memória - e, acrescentamos aqui, a partir de uma perspectiva sobre cognição que não é compatível com os princípios sobre linguagem que, supomos, Adam adota (mesmo se considerarmos que seja possível uma abordagem interdisciplinar). É certo que Adam, no desenvolvimento de seus estudos, a partir de 90, especialmente, considera padrões genéricos, scripts, conhecimentos prototípicos de sequências narrativas, argumentativas etc. - este é um ponto importante, aliás, de sua teoria de sequências textuais. Contudo, embora esses elementos pressuponham uma certa estruturação e hierarquização de conteúdos, esses conhecimentos não têm a mesma natureza das regras gramaticalizáveis dos modelos das gramáticas textuais. Nas palavras de Charolles:

\begin{abstract}
Torna-se evidente que uma gramática de texto fundamentada na ideia ingênua de que existe um critério de boa formação textual, comparável ao da gramática da frase, está condenada a formular regras que se provarão falhas na primeira ocasião. Essa constatação torna mais ou menos obsoleto todo projeto de gramática de texto. Nada impede, no entanto, que se tente dar conta das operações realizadas pelos indivíduos, ao calcular a coerência de uma sequência de enunciados, já que (por princípio) deve haver coerência. Daí a evolução das gramáticas de texto para modelos ditos procedurais, projetados para descrever os cálculos efetuados pelos interpretantes, para resolver a coerência de uma sequência. (CHAROLLES, 1989, p. 12)
\end{abstract}

Desde então, as discussões de Adam evoluíram, segundo o próprio autor, especialmente no que diz respeito a renunciar à descontextualização e a rejeitar uma dissociação radical entre texto e discurso (ADAM, 2005). O refinamento da ideia de articulação necessária entre texto e discurso passa pela questão de que forma e sentido aparecem como propriedades associadas, necessárias e simultâneas, inseparáveis, no funcionamento da língua, conforme afirma Adam (2008), referindo Benveniste (1966).

Mas além disso, conforme a percepção que esperamos mostrar aqui neste artigo, sua contribuição para os estudos do texto ultrapassa a mera questão de definir texto, contexto e discurso: Adam amarra esses conceitos à teoria da linguagem de Benveniste, de modo a constituir uma sólida proposta para os estudos do texto e para a análise textual.

E para demonstrar e fundamentar sua teoria e método de análise, Adam vai ainda mais longe, para buscar suas raízes, afirmando que a linguística textual é também uma continuadora da definição de discurso que nos apresentam linguistas fundadores, como, antes de Benveniste, Ferdinand de Saussure. Adam (2005; 2008) retoma, então, Saussure, o que repetimos aqui, a seguir, pois é preciso conhecer a discussão entabulada por Saussure para entender, na sequência, os deslocamentos promovidos por Benveniste e, consequentemente, por Adam.

\title{
Retorno aos princípios fundadores
}

Sem a ambição de propor uma abordagem revolucionária, Adam (2005) tem o intuito 
de fornecer instrumentos para a compreensão das produções discursivas humanas. Ao propor uma análise textual dos discursos, afirma o autor que a análise textual ultrapassa a análise do discurso, na medida em que seu objetivo não é somente descrever os discursos pelo viés dos meios linguísticos ou paralinguísticos mobilizados, mas também o de construir uma compreensão da própria produção de sentido, isto é, das operações necessárias à realização do sentido produzido. E aqui também se revela o nosso interesse pelo trabalho de Adam, pois são comuns propostas de análises textuais em que são feitas "interpretações de texto", o que é válido, mas, nessas propostas, nem sempre são evocados fundamentos ou critérios objetivamente textuais de análise. Diferentemente disso, Adam se compromete com uma pesquisa, cuja visada é, através de categorias textuais, a compreensão e organização do sentido no texto, e não somente uma interpretação sobre o sentido que é produzido pelos textos.

Adam (2005) afirma que não apresenta, em sua obra, uma teoria unificada original, mas as grandes linhas de uma abordagem eclética. Contudo, para o autor:

\footnotetext{
O texto é certamente um objeto empírico tão complexo, que sua descrição poderia justificar o recurso a teorias diferentes, mas é de uma teoria deste objeto e de suas relações no domínio mais amplo do discurso em geral que temos necessidade, para dar aos empréstimos de conceitos das diferentes ciências da linguagem um novo quadro e uma indispensável coerência. (ADAM, 2005, p. 4)
}

Vê-se nessas palavras que, embora admitindo a necessidade de recorrer a diferentes ciências para explicar o fenômeno do texto, sob o ponto de vista que pretende, Adam pontua a questão crucial de que é preciso "uma teoria deste objeto e de suas relações no discurso". Em uma extensão dessa afirmação, podemos dizer que é preciso pensar o texto a partir de suas próprias categorias. E é com uma crítica dos fundamentos da Linguística Textual que ele inicia sua empreitada.

\section{Recomeçar de Saussure}

Adam lembra, inicialmente, que Saussure colocou a língua como centro de seu programa, mas também se perguntou sobre o que separa a língua propriamente dita do discursivo. Saussure falou aliás, de "linguagem discursiva" e observou que é neste domínio que a frase existe, enquanto que a palavra vive fora do discurso, no tesouro mental dos falantes.

Em Nota sobre o discurso, Saussure explica que o sujeito falante não se exprime por palavras isoladas, mas que o discurso consiste na configuração de um elo entre dois conceitos que se revestem de forma linguística. A língua apresentaria apenas conceitos em suspenso, que esperam para ser postos em relação e, assim, haja significação.

Para Adam, essa nota de Saussure lembra o diálogo O sofista, de Platão, o qual certamente Saussure teria lido e que traz uma definição de logos-discurso, em que estaria implicada uma operação de ligação: nomes "enfileirados" simplesmente não produzem 
discurso, mas dependem de um entrelaçamento entre os constituintes.

Adam menciona também Humboldt (1903-1936), o qual teria radicalizado essa ideia, antes de Saussure, afirmando que "a língua consiste somente no discurso conectado, a gramática e o dicionário são comparáveis ao seu esqueleto morto".

Conforme Adam, ainda que a nota defina o discurso como funcionamento da língua e como uma proposta interativa de sentido, de um sujeito se dirigindo a outro, e como ligação entre conceitos revestidos de forma linguística, nela não são esclarecidas a natureza e a extensão desses encadeamentos. É em outras fontes que Adam encontra algum eco para esta questão, por exemplo, na lição de 30 de junho de 1911 (publicada por Bouquet, em Introdução à leitura de Saussure). Neste texto, então, aparece a seguinte formulação: seriam duas as ordens de ligação entre as palavras: fora da fala, os signos "prontos na língua", que têm alguma coisa em comum, estariam em relação associativa; na fala, as palavras estariam submetidas a outro tipo de relação, dependente de seu encadeamento, que seriam as relações sintagmáticas.

No Curso de Linguística Geral, Saussure (1974) também reconhece que, mesmo tendo sustentado a frase como unidade máxima da sintagmatização, há um problema: ao mesmo tempo em que a frase pertence à fala, e não à língua, seria preciso considerar as duas esferas, do sintagma e da associação, para explicá-la. Na sintaxe, há algo que flutua, disse Saussure, entre o que é dado e fixado na língua e o que é deixado à iniciativa individual. Assim, haveria algo delicado na frase, por se situar na "fronteira dos dois domínios", conforme indicou Saussure.

Mas, de acordo com Adam, Saussure tinha como principal preocupação as operações necessárias para abstrair o sistema da língua a partir dos fatos do discurso. Já Benveniste retoma a questão de maneira "exatamente inversa, privilegiando a realização do discurso, o que ele vai progressivamente designar como enunciação" conforme Adam (2005).

E aqui inaugura-se um novo ponto desta investigação, que diz respeito ao que se pode considerar, talvez, como o grande passo em direção a uma linguística textual.

\section{Benveniste e a constituição de uma nova linguística}

Para Adam, Benveniste se mantem muito próximo de Saussure no que diz respeito às relações associativas e sintagmáticas, o que se comprova no seguinte trecho:

O "sentido" (na acepção semântica [...]) se realiza em e por uma forma específica, a do sintagma, diferentemente do semiótico, que se define por uma relação de paradigma. De um lado, a substituição, do outro, a conexão, tais são as duas operações típicas e complementares. (BENVENISTE, 1974, p. 35)

Também o autor permanece próximo da nota sobre o discurso, quando afirma que "é no discurso, atualizado em frases, que a língua se forma e se configura. Aí começa a linguagem" (BENVENISTE, 1966, p. 131). Contudo, Benveniste instaura, nas suas próprias palavras, "uma divisão fundamental completamente diferente da que Saussure tentou entre 
língua e fala" (BENVENISTE, 1974, p. 224), e distingue os domínios do semiótico e do semântico:

\begin{abstract}
Na realidade, o mundo do signo é fechado. Do signo à frase não há transição, nem pela sintagmatização nem de outra maneira. Um hiato os separa. É preciso admitir então que a língua comporta dois domínios distintos, em que cada um requer seu próprio aparelho conceitual. Para aquele que nós chamamos semiótico, a teoria saussureana do signo linguístico servirá de base para a pesquisa. O domínio semântico, por outro lado, deve ser reconhecido como separado. Haverá a necessidade de um aparelho novo de conceitos e de definições. (BENVENISTE, 1974, p. 65)
\end{abstract}

Ao retornar à questão da frase, Benveniste a remete para além do último nível de combinações do sistema da língua: "com a frase um limite é superado, entramos em um novo domínio (...) Ela se distingue fundamentalmente de outras entidades linguísticas" (BENVENISTE, 1966, p. 128). Se de um lado, então, a frase pode ser decomposta em constituintes, por outro, ela não pode integrar uma unidade de ordem superior de complexidade - pelo menos não do mesmo modo como seus componentes a constituem.

Diante desse novo modelo de domínio do semiótico e do semântico, podemos então situar a frase não exatamente numa fronteira, mas na interdependência desses dois domínios. Essa dependência mútua se confirma também no seguinte trecho:

\footnotetext{
A forma de uma unidade linguística define-se como sua capacidade de se dissociar em constituintes de nível inferior.

O sentido de uma unidade linguística define-se como sua capacidade de integrar uma unidade de nível superior.

Forma e sentido aparecem assim como propriedades conjuntas, dadas necessárias e, simultaneamente, inseparáveis no funcionamento da língua. Suas relações mútuas se revelam na estrutura dos níveis linguísticos, percorridos pelas operações descendentes e ascendentes da análise, e graças à natureza articulada da linguagem. (BENVENISTE, 1966, p. 126-127)
}

Adam considera que, ao definir as propriedades da forma e do sentido como conjuntas e inseparáveis no funcionamento da língua e afirma que "ao fazer da proposição a unidade de última ordem integrativa, Benveniste situa perfeitamente os limites da linguística do sistema." (ADAM, 2008, p.37).

É interessante observar, aqui, que Adam escolhe o termo proposição em vez de frase. Em Benveniste, como se pode observar nos trechos citados, frase tem um outro sentido, que não mais o de uma sequência de ordem meramente sintática ou tipográfica, e assume um novo estatuto, indissociável de seu aspecto semântico e do seu emprego em um enunciado. Por isso, supomos que a escolha de Adam pelo termo proposição seja guiada pela ressignificação de frase promovida por Benveniste, e, sem dúvida, marca o deslocamento promovido, então, por Adam. Contudo, nesta parte do livro de Adam, não consta nenhuma explicação que esclareça essa decisão, o que seria necessário diante da concepção histórica a que remete o termo proposição, situando-o no âmbito da filosofia e da lógica. Mais adiante a questão sobre frase, proposição e enunciado e sobre quais unidades podem ser consideradas 
como textuais será retomada, com detalhe, na obra de Adam. Sob o risco de fugir do escopo, mencionamos essa discussão neste artigo apenas para pontuar o percurso feito pelo autor e não nos aprofundamos nela. Entretanto vemos a necessidade de adiantar aqui uma parte importante dessa explicação no que diz respeito em específico ao deslocamento da noção de proposição: não se trata da proposição lógica ou gramatical, para Adam, mas de uma proposição enunciada, pois que seu sentido é construído discursivamente, na enunciação.

Retomando a argumentação do autor sobre a relação da frase com o texto, observamos que Adam (2008) recorre a Olivier Soutet para afirmar que no texto a relação do todo com a parte não pertence ao mesmo tipo de previsibilidade que existe entre cada uma das unidades subfrasais e seus constituintes imediatos. Notamos que, para esta constatação, embora Adam não o mencione, é interessante buscar suporte também em Benveniste (1974), quando o autor postula que o emprego das formas é muito diferente do emprego da língua: enquanto que no primeiro o inventário de combinações tende a ser limitado, no segundo, na língua em funcionamento, ele é sempre novo, diferente e imprevisível. Isto é, as relações no domínio semântico são diferentes das que ocorrem no domínio do semiótico; contudo, na língua em funcionamento, os dois planos são solicitados e trabalham conjuntamente.

Neste ponto da discussão, pode-se concluir, com Benveniste, que a frase é uma unidade de outra ordem e realmente pertence ao discurso. E além disso, para Adam $(2005 ; 2008)$, Benveniste faz dessa unidade o centro de outra linguística.

Fica evidente, neste percurso realizado por Adam, o quanto a frase é o conceito fulcral que instigou - e continua colocando problemas para - a discussão sobre o que acontece quando a língua se converte em discurso. A questão da frase assume assim um lugar de destaque para o trabalho que apresento aqui e para a linguística textual, pelo fato de suscitar as questões que se colocam na fronteira entre o domínio da língua e o domínio do discurso.

\section{A translinguística de Benveniste}

Outra chave para o que permite desenvolver uma linguística textual, para Adam, está na interpretação que o autor faz da reflexão de Benveniste, especialmente sobre o que é publicado no texto Semiologia da língua e o que foi delineado em Aparelho formal da enunciação, em que Benveniste distingue uma linguística da língua sistema - ou semiótica cuja unidade é o signo, e uma linguística do discurso - ou semântica - cuja unidade é a frase. Para Adam (2011), Semiologia da língua fixa o quadro epistemológico de Aparelho formal da enunciação.

Inicialmente, pontua Adam, Benveniste teria excluído o texto do campo semântico da linguística do discurso. A teoria da enunciação, que teria lugar no âmbito da linguística do discurso, tem como objeto a produção de enunciados, e não o texto do enunciado. Por isso, é convocado um terceiro ramo da linguística para assumi-lo.

Em conclusão, é necessário ultrapassar a noção saussuriana do signo como princípio único, do qual dependeria, simultaneamente, a estrutura e o funcionamento da 
língua. Essa ultrapassagem far-se-á por duas vias:

- na análise intralinguística, pela abertura de uma nova dimensão de significância, a do discurso, que denominamos semântica, de hoje em diante distinta da que está ligada ao signo e que será semiótica;

- na análise translinguística dos textos, das obras, pela elaboração de uma metassemântica que se construirá sobre a semântica da enunciação. (BENVENISTE, 1969, p. 67)

Para Adam, Benveniste dividiu programaticamente o campo geral da linguística, conforme o diagrama que copiamos, a seguir.

Figura 1 - Esquema de Adam para a divisão programática de Benveniste

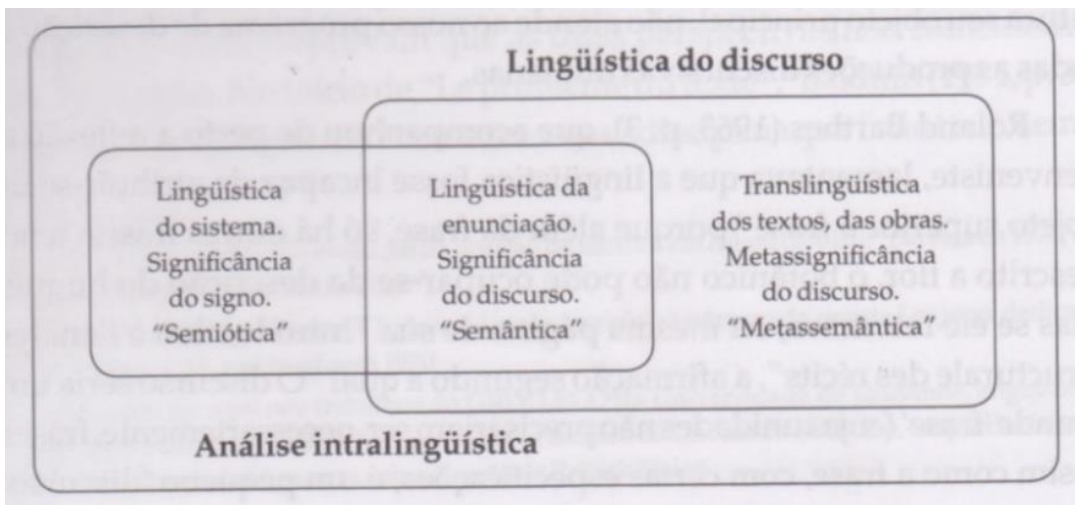

Fonte: Adam (2008, p. 39).

Observamos que em Bühler (1932) já havia indicações dessa necessidade de encontrar um lugar na linguística para os fenômenos da parole - ou do discurso, como passamos a denominar, com Benveniste e Adam, o âmbito da língua em funcionamento. Tendo como fonte a distinção saussureana entre langue e parole ${ }^{2}$, Bühler distingue quatro aspectos da linguagem, como diferentes modos de manifestação, que seriam Sprechhandlung (ação verbal), Sprachwerk (produto linguístico), Sprachgebilde (forma linguística) e Sprechakt (ato verbal). À parte da complexa explicação desses conceitos, que também foge aos propósitos deste artigo, o que ressalto aqui é a preocupação de Bühler em apontar para uma distinção no tratamento de diversos aspectos da linguagem, entre eles, o do produto linguístico Sprachwerk de uma ação verbal (Sprechhandlung), que pertenceriam à parole, mas que não são vistos como entidades autônomas e separáveis dos aspectos mais formais, Sprachgebilde e Sprechakt, que estariam relacionados à langue.

Coseriu (1952), em seu conhecido texto Sistema, norma e fala, faz uma profunda discussão desse esquema dos aspectos da linguagem propostos por Bühler, questionando as interpretações e os desenvolvimentos rigidamente dualistas de doutrina saussureana, para colocar em evidência a necessidade de incluir os aspectos da atualização ou realização da

\footnotetext{
${ }^{2}$ Esta distinção bühleriana entre quatro aspectos da linguagem tem sua fonte, além da distinção saussureana, entre langue e parole, na de Humboldt, entre ergon e energeia, na fenomenologia husserliana e na sua concepção de ato significante e, finalmente, na hermenêutica de Dilthey. No entanto, para as observações que pretendemos aqui, fazer um aprofundamento dessa vasta referência seria demasiado.
} 
língua ao lado de seus aspectos mais sistemáticos.

Com essas observações, o intuito aqui é apenas o de sugerir que o programa de Benveniste não é fruto de uma obra isolada, mas sobretudo se inclui numa discussão já encetada por outros grandes autores, como Bühler e Coseriu, que se debruçaram sobre os problemas da linguagem e, neste caso especial, sobre se os fenômenos da parole podem ser objeto da ciência linguística e como podem aí se enquadrar. Contudo - e isto são especulações que fazemos neste trabalho - Adam recorre a Benveniste pelo fato de que sua proposta para a linguagem não apenas supera o questionamento sobre a indissociabilidade entre langue e parole, mas inclui uma explicação coerente para o que permite pensar os fenômenos do discurso à luz de uma teoria enunciativa. Isso fica evidente no esquema acima esboçado por Adam da proposta de Benveniste, conforme a Figura 1, em que a linguística do discurso inclui a linguística da enunciação e a translinguística, a qual, por sua vez abrigaria a linguística textual. Por outro lado, a linguística da enunciação está colocada como contraparte indissociável da linguística do signo, compondo o fundamento para uma análise intralinguística. O movimento de Benveniste, assim representado por Adam, propicia, a nosso ver, o fortalecimento de uma mudança radical para a linguística.

Como se sabe, a doença que acometeu Benveniste no início dos anos 70 o impediu de dar seguimento a essas questões. Assim, Adam traça um roteiro de outros autores, cuja interpretação do programa de Benveniste floresceu, dando origem a diferentes abordagens.

Adam (2019) cita Meschonnic como um dos poucos linguistas a falar sobre essa terceira dimensão de significância e que teria inclusive inscrito sua poética na perspectiva da "translinguística das obras". Também menciona Barthes, que teria feito a surpreendente afirmação de que Benveniste teria sido o "único linguista textual", ao fazer a junção entre a linguística e a textologia. Sobre Kristeva e Todorov, Adam (2011; 2019) observa que foi tão forte a impressão causada por Benveniste nestes dois autores, que os escritos do círculo de Bakhtin foram traduzidos e transpostos em termos enunciativo-discursivos, o que induziu uma falsa continuidade com a posição de Benveniste.

Mostrando as diferentes perspectivas desses autores, Adam abre caminho, então, e apresenta o seu próprio entendimento do programa de Benveniste para o texto.

\section{O encaminhamento de Adam rumo ao estabelecimento do texto e à construção do objeto de análise}

Situando a linguística textual nesta leitura do programa sugerido por Benveniste, conforme o diagrama mostrado pela Figura 1, Adam (2005; 2008; 2019) discute as diversas perspectivas, a partir das quais se pode pensar o texto. $E$, ainda que seu estudo seja centrado na textura e na estrutura composicional dos textos, propõe uma abordagem unificada e interdisciplinar das sequências textuais, o que, em sua proposta, significa levar em conta aspectos sociodiscursivos e de gênero, além de aspectos semânticos, pragmáticos e enunciativos em suas análises.

Adam $(2005 ; 2008 ; 2019)$ define texto, unidades textuais e categorias de análise, a 
partir da sugestão de Benveniste de "um novo aparelho de conceitos e de definições". O autor considera as ponderações de Coseriu para a noção de nível dos textos, em que os textos se situariam em um nível, em relação ao nível da linguagem e das línguas. Textos seriam "séries de atos linguísticos conexos que realiza um dado locutor em uma situação concreta que, naturalmente, pode tomar uma forma falada ou escrita" (COSERIU, 2007, p. 86). A isso, teria acrescentado Rastier (1989) que "a linguística dos textos se distingue da linguística das línguas e a fortiori da linguística da linguagem, mas a comanda, todavia: só se pode inventariar os signos e suas funções descrevendo os textos". O objeto da linguística textual é o nível individual da linguagem, completa Adam (2019), mas também abrange o que diferentes textos de um corpus têm em comum, mesmo que de maneira potencial e/ou hipotética. Daí o interesse do autor em comparações de classes de textos.

Outra questão que justifica a abordagem de Adam para o texto pode ser encontrada em Coseriu (2007, p. 300), que afirma: "sendo o texto algo do individual (...) a linguística do texto difere tanto da linguística em geral quanto da gramática transfrástica". E acrescenta: "apenas o fato de existir uma classe de conteúdo que é propriamente um conteúdo textual, ou um conteúdo dado através dos textos, justifica a autonomia do nível textual. É por essa razão que a linguística textual é uma linguística do sentido" (COSERIU, 2007, p. 156). Definindo, a partir daí, o texto como uma unidade semântica, Adam (2019) explica que sua análise textual dos discursos é chamada a compreender os modos de organização da produção dos sentidos dos textos em contexto.

Sua obra parte da observação de que "não se pode decompor o texto em frases, aplicando-lhe os mesmos procedimentos aplicados na frase, no sintagma, no signo e no morfema" (Adam, 2019, p. 19). Por isso, é preciso uma mudança no quadro teórico.

Numa investigação, então, de como a frase chega ao texto, Adam (2019) constata, ao lado de autores como Ray Jackendoff e Peter Culicover, que é preciso considerar uma sintaxe num sentido amplo, que inclui outras unidades, como estruturas praxeológicas, por exemplo.

Além disso, quando se ultrapassa o nível sintagmático da frase, outros sistemas de conexões aparecem, afirma Adam (2008, p. 75). Sobre essas conexões textuais, apoia-se em Charolles (1993), para descrever duas de suas propriedades essenciais, quais sejam, 1) a de que repousam sobre a ocorrência de marcas instrucionais que indicam ao destinatário como devem ser compreendidas as relações entre uma unidade e outra, e 2) a de que funcionam à longa distância e não têm esquemas preestabelecidos, "o que faz com que o discurso, ao contrário da frase, seja uma entidade estruturalmente aberta", nas palavras de Charolles (1993, p. 311).

Assim, e com a convicção de que é possível elencar uma espécie de repertório de opções que estariam a serviço dos projetos comunicativos dos falantes, Adam (2008) se propõe a elaborar conceitos específicos e definir classes de unidades "intermediárias" entre a língua e o texto, conforme sugere Combettes (1992). O estudo das configurações dessas unidades é para Adam (2019) o próprio objeto da linguística textual e a isso se dedica longamente, chegando às seguintes operações de segmentação e de ligação textuais, que aparecem no esquema a seguir: 
Figura 2 - Esquema das operações de textualização

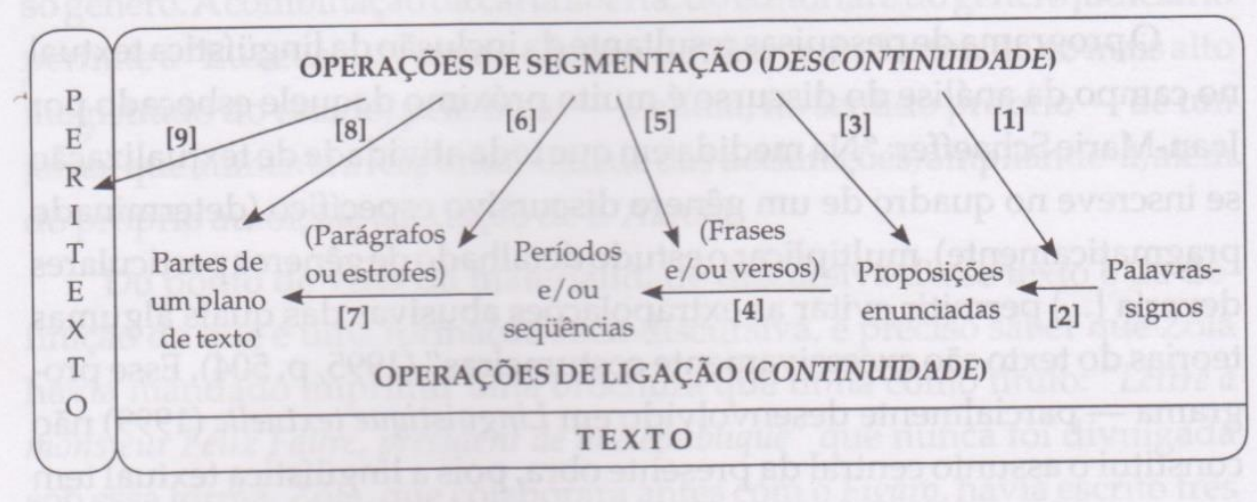

Fonte: Adam (2008, p. 64).

É interessante notar que, para Adam (2019), o primeiro critério de classificação que se opera em um texto, "uma vez que um efeito de texto é percebido" por um leitor ou ouvinte é o do gênero discursivo, a partir do conhecimento que este leitor ou ouvinte tem do sistema de gêneros de sua comunidade discursiva e, eventualmente, do conhecimento de gêneros de outras comunidades e de outras épocas. Ao delimitar o alcance de sua análise textual dos discursos, o autor anunciava, já em sua obra de 2005, que a linguística textual, em sua proposta, pertenceria a um subdomínio de um campo mais vasto da análise das práticas discursivas, o que também pode ser visualizado na Figura 2.

No entanto, as questões sobre gêneros do discurso, que pressupõem uma interação social, o interdiscurso e as formações sociodiscursivas, que constituem o que Adam designa como peritexto, não são o centro do estudo proposto pelo autor, ainda que sejam prérequisitos de análise. A tarefa da linguística textual para Adam diz respeito às unidades e agenciamentos textuais. Isto é, diz respeito a compreender as operações de segmentação e de conexão dos textos, de acordo com os planos de texto, parágrafos ou estrofes, períodos e/ou sequências, frases ou versos e proposições enunciadas, sendo esta última a que Adam considera como unidade textual mínima.

Para compreender como o autor chega a essa proposta, e quais as unidades de segmentação que elege para o seu trabalho, refazemos um passo-a-passo resumido de seu raciocínio, a seguir. $\mathrm{O}$ autor discute, em primeiro lugar, possíveis operações de segmentação do texto.

As operações de segmentação

Apoiando-se em Prandi (2007), Culioli (1984) e em Berrendonner (2002), Adam (2008) defende que é preciso transpor "a fronteira do núcleo da frase simples para abordar os produtos naturais da interação linguageira, que são os textos". Além disso, observa que a unidade textual de base não é garantida pela frase, o que ele comprova, partindo de uma discussão sobre construções deslocadas e relativas. Adam (2008, p.83) pontua que em sua 
perspectiva "fatos sintáticos são sempre considerados em suas relações com os efeitos textuais" e mostra, com vários exemplos, que as frases segmentam unidades semânticas diferentes, como podemos observar em:

Exemplo 1: [e1]Tendo derrubado o cartazeiro Achille, [e2]eles o arrastaram ao longo de toda a ponte de Alfortville, [e3]depois o jogaram lá de cima. (ADAM, 2008, p. 85)

Nesse exemplo, o organizador temporal depois e o verbo no pretérito, em [e3] indicam uma sucessão temporal de ações, como é próprio da narrativa. Em [e1], a construção deslocada "Tendo derrubado o cartazeiro Achille", mesmo que se trate de uma estrutura reduzida, estabelece com o sujeito uma relação idêntica à de uma predicação completa; neste caso, constitui outra proposição narrativa que introduz uma relação temporal de anterioridade entre as ações dos agressores em derrubar Achille e depois arrastá-lo (conforme a proposição narrativa [e2]), antes de jogá-lo (conforme a proposição [e3]).

Além disso, o exemplo 1 ilustra o fato de que uma frase tipográfica pode constituir até mesmo uma unidade de sentido suficiente para ser um texto completo.

Outros exemplos explorados pelo autor, também de breves ${ }^{3}$ de Félix Fénéon, são:

Exemplo 2: Assim que aspirou sua pitada de rapé, A. Chevrel espirrou e, ao cair da carroça de feno que reconduzia de Pervenchères (Orne), faleceu.

Exemplo 3: No lago de Annecy, três jovens nadavam. Um, Janinetti, desapareceu. Mergulharam os outros. Eles o resgataram, mas morto. (ADAM, 2008, p. 84)

Nos exemplos 2 e 3, vê-se que, apesar da grande semelhança narrativa, os trechos não são segmentados da mesma maneira.

Em uma análise da perspectiva funcional da frase, Adam $(2005 ; 2008)$ explora a progressão tema/rema. Um dos exemplos citados pelo autor é o de um anúncio publicitário de uma rede de supermercados:

Exemplo 4: É com morangos recém colhidos que gostamos de preparar a geleia Favorit Premium. Seu conteúdo em frutas de primeira qualidade é, assim, particularmente elevado uma boa razão para também experimentar as outras variedades Favorit Premium. (ADAM, 2008, p. 93)

Neste exemplo, Adam explica que a construção clivada acentua o valor do rema e permite apresentar os "morangos recém colhidos" como melhores e distintos de todos os outros morangos, os quais seriam menos frescos. Tal procedimento é uma estratégia explorada pela publicidade, para destacar o produto.

Também em outras situações, o procedimento de destacar por clivagem pode desempenhar uma focalização interessante, como nesta declaração de Sarcozy, de um de seus pronunciamentos de 2007, reproduzida por Adam:

\footnotetext{
${ }^{3}$ Sob a rubrica Nouvelles en trois lignes, as breves foram uma colaboração de Félix Fénéon para a seção de fait divers (notícias do cotidiano) do jornal francês Le Matin, em 1906.
} 
Nesta frase, o rema "buscar o crescimento" é destacado e anaforizado e torna-se o tópico do discurso, sobrepondo-se ao sujeito sintático da frase.

A construção passiva, como no exemplo a seguir, da seção de fait divers de um jornal francês, também é, de acordo com Adam (2008) um outro modo de tematizar ou rematizar diferentes grupos sintático-semânticos, modificando o foco e hierarquizando a importância dos agentes, pacientes ou da própria ação.

\section{Exemplo 6: Devorado por porcos...}

Na Romênia, um garotinho de 2 anos é comido por porcos, enquanto queria alimentá-los.

... e por lobos

Um bebê de seis meses foi devorado, na noite de segunda para terça, por lobos famintos num vilarejo da região de Saveh, ao sul de Teerã. Duas outras crianças já foram atacadas, há alguns dias, por lobos, neste vilarejo. (ADAM, 2008, p. 95)

No exemplo 6, a ação e o agente são tematizados, ao passo que se enfraquece a figura do paciente-vítima.

Por fim, para mais um exemplo, Adam (2008) recorre às acumulações de aposições, que expandem o sujeito, como neste soneto de Baudelaire:

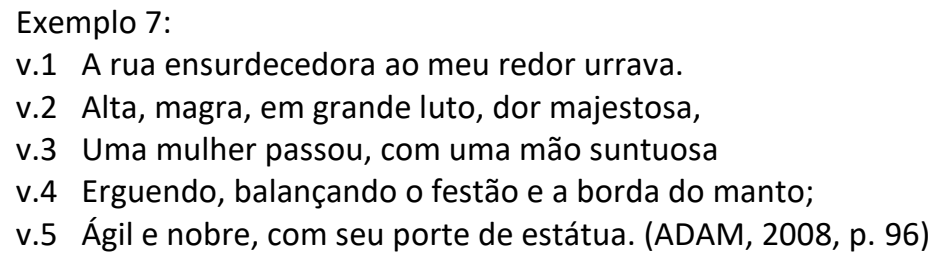

Nestes versos, Adam destaca a autonomia assumida pelo verso 5 , mesmo que ligado sintaticamente ao verso 3, em que "uma mulher" aparece como foco temático. A predicação do verso 5 é, além disso, um prolongamento das predicações antecipadas no verso 2 . Contudo, desempenha um papel, não mais de retardar a introdução do tema, pois que se pospõe; o que ocorre é que o verso 5 substitui o tema, autonomizando-o. É a imagem da mulher como ágilnobre-estátua que se instaura como tema no verso 5.

Assim, afirma Adam:

A fraca carga de informação do tema faz dele uma base de retomada e, portanto, de coesão textual. Uma sequência de enunciados (parágrafo ou sequência) pode ser definida como uma sequência de temas. Todo texto é entendido em uma tensão entre coesão (ligada à estrutura temática, à conexão e à concatenação dos temas sucessivos) e progressão. Os remas sucessivos trazem as informações pertinentes, mais importantes, ditas, nesse sentido, "novas" ("foco" ou centro de informação). Ao se atribuir a esses conceitos um lugar na dinâmica textual, vai-se além da divisão da frase em tema (Th) e rema (Rh), para insistir na escolha do ponto de partida (Th) de cada novo enunciado. (ADAM, 2005, p. 96-97)

O que se observa nesses exemplos de progressões tema/rema é que as ligações que estabelecem sentido não se dão necessariamente de uma frase a outra, mas são estabelecidas 
relações prospectivas e retrospectivas entre trechos mais distantes ou mais próximos, constituindo-se como "encadeamentos de enunciados na liberdade da cadeia verbal" (ADAM, 2005, p. 63) Além disso, o jogo de focalização, apagamento e retomada não se restringem a movimentos internos meramente frasais, mas se estabelecem com relação àquilo que representa tais movimentos em relação aos outros segmentos do enunciado. Por essas razões, afirmamos, com Adam (2008) que a análise de progressões em tema e rema extrapolam a teoria da frase.

Adam conclui, com estes e outros vários exemplos que analisa, que a estrutura sintática da frase não apresenta uma estabilidade suficiente para ser considerada como unidade de análise textual. Para o autor, ela deve ser substituída por uma unidade mais leve, cuja segmentação no discurso seja extremamente variada e profundamente significante. Rejeita, então, a frase do domínio do sistema estrito da língua, pois o que pertence ao texto é a "frase enunciada".

A opção do autor é, então, adotar a unidade textual mínima que marca a natureza do produto de uma enunciação: o enunciado. E acrescenta a isso a designação de uma microunidade sintático-semântica, a que o conceito de proposição atende bem. Assim, é definida uma unidade não tão virtual como a proposição dos lógicos ou a dos gramáticos, mas uma unidade efetivamente realizada e produzida por um ato de enunciação, como um enunciado mínimo.

Para designar os conjuntos mais ou menos complexos de proposições-enunciados que entram numa composição textual, o conceito de período, de acordo com o autor, traz a vantagem de dar conta das conexões lógico-gramaticais, assim como as rítmicas, dadas pelo e no discurso. É aí que o autor defende, então, o período como unidade textual, considerandoo, junto com Tamine (2003), como uma célula de construção do texto, análoga à estrofe em poesia.

O exemplo a seguir é de uma passagem retirada de um famoso discurso do general De Gaulle, em Argel, em 4 de junho de 1958, que se constitui, na proposta de Adam, como um período:

Exemplo 8: (...) em toda a Argélia // não há senão uma única categoria de habitantes /// não há senão franceses /// totalmente // franceses totalmente // com os mesmos direitos // e os mesmos deveres /// (ADAM, 2008, p. 209)

Esse período, explica Adam, está estruturado por paralelismos e repetições ("não há senão", "totalmente" e "os mesmos") e é amplamente determinado pela interação, em especial pelos aplausos que interrompem a fala do então presidente da França. Algumas repetições são inclusive causadas por essas interrupções. Na transcrição acima, os sinais de barra (/) indicam a duração das pausas, o que também dá uma ideia do ritmo da fala.

Outro tipo de agrupamento complexo de proposições-enunciados proposto por Adam, além do período, é a sequência. Se nos períodos o agrupamento de proposições-enunciados é menos passível de tipificação e mais livre de uma pré-configuração, nas sequências, os agrupamentos de proposições-enunciados que a compõem dependem mais de certas 
configurações já estabelecidas (discursivamente), pois que suas relações macrossemânticas foram "memorizadas por impregnação cultural (pela leitura, escuta e produção de textos) e transformadas em esquema de reconhecimento e de estruturação da informação textual", nas palavras de Adam (2008, p. 204). Para ilustrar melhor essa diferença, podemos dizer que as diferentes combinações de uma macroproposição (agrupamento de proposiçõesenunciados) na composição de uma sequência são o que determinam dizer se a sequência é narrativa, argumentativa, explicativa ou dialogal ${ }^{4}$.

Entre uma sequência mínima e um período complexo, a diferença está no que diz respeito à complexidade da organização das proposições-enunciados: os períodos apresentam uma organização interna menos previsível, mais livre, e entram diretamente na composição de partes de um plano de texto (ver o esquema da Figura 2); já as sequências são compostas de um número limitado de conjuntos de proposições-enunciados ou macroproposições que seguem algum esquema mais tradicionalmente correspondente a certas ações, como as de narrar, argumentar, explicar ou dialogar.

Além do período e da sequência, mais duas unidades de segmentação, de natureza mais tipográfica, ocupam um nível intermediário, quais sejam, a frase e o parágrafo, na prosa, e o verso e a estrofe na poesia. Os blocos segmentados por essas unidades são porções de texto de tamanho variável e dão origem ao que Adam (2019) vai nomear como períodos.

Não esgotamos aqui todo o estado da arte que é feito pelo autor, em que ele questiona em especial as noções bastante fixadas historicamente de frase, proposição, enunciado e período, para chegar às categorias que aqui apresentamos apenas brevemente. Isso porque nosso intuito é de fazer uma primeira reflexão sobre a compatibilidade e coerência da proposta do autor no que diz respeito ao programa linguístico de Benveniste, que poderia fundar, então, a linguística textual, tal como propõe Adam.

Para completar a resenha das operações de textualização propostas por Adam, apresentamos, a seguir, as operações de ligação entre os segmentos, que, ao lado das operações de segmentação, devem ser objeto de atenção do linguista do texto, conforme o autor.

As operações de ligação

Quando se ultrapassa o nível sintagmático da frase, "outros sistemas de conexões aparecem", afirma Adam (2008, p. 75). Sobre essas conexões textuais, o autor apoia-se novamente em Charolles (1993), para descrever duas de suas propriedades essenciais, quais sejam, 1) a de que repousam sobre a ocorrência de marcas instrucionais que indicam ao

\footnotetext{
${ }^{4}$ Para uma melhor compreensão da noção de tipo/protótipo de texto narrativo, argumentativo, explicativo, descritivo e dialogal, ver Adam (2019). O caso particular das proposições descritivas, contudo, indica que os segmentos descritivos não apresentam uma organização interna tão estável se comparável à das proposições argumentativas, explicativas ou narrativas. No caso da descrição, segundo Adam (2008), trata-se menos de uma organização estrutural e mais de um repertório de operações e, portanto, verifica-se aí uma composição sequencial menos rígida, mais periódica, e não macroproposicional.
} 
destinatário como devem ser compreendidas as relações entre uma unidade e outra, e 2) a de que funcionam à longa distância e não têm esquemas preestabelecidos, "o que faz com que o discurso, ao contrário da frase, seja uma entidade estruturalmente aberta", nas palavras de Charolles (1993, p. 311).

Assim, e com a convicção de que é possível elencar uma espécie de repertório de opções que estaria a serviço dos projetos comunicativos dos falantes, Adam (2008) se propõe a elaborar conceitos específicos e definir classes de unidades "intermediárias" entre a língua e o texto, conforme sugere Combettes (1992).

Adam (2008, p.88) busca "descrição dos movimentos textuais de focalização, retomada e progressão dos enunciados" e, por isso, para a análise textual, além da segmentação em unidades, é preciso entender como elas se relacionam e se determinam.

Conforme o autor, há cinco grandes tipos de operações que garantem o agrupamento das proposições-enunciados. Essas operações são combináveis entre si e unem tanto os constituintes de proposições próximas, quanto têm uma ação a longa distância. Além disso, podem ser prospectivas ou retrospectivas.

O seguinte esquema, reproduzido aqui, ilustra as cinco operações de ligação elencadas pelo autor:

Figura 3 - Operações de ligação que asseguram a continuidade textual:

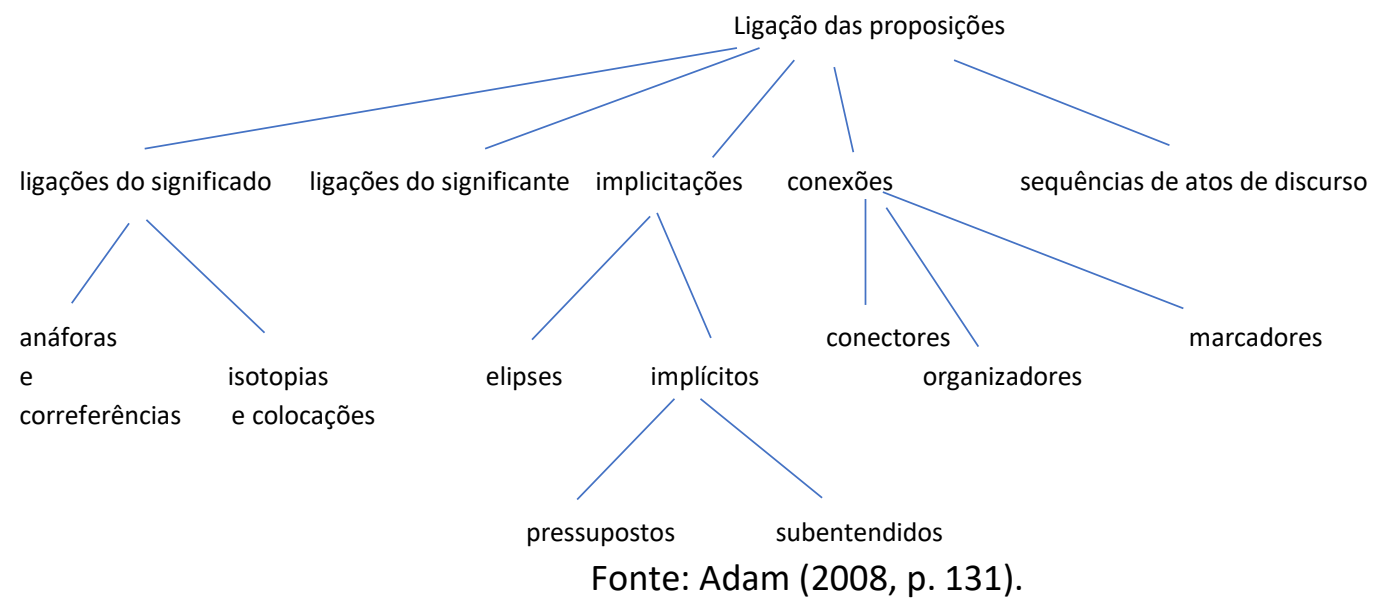

Isoladamente, nenhuma dessas operações garante a coerência de um texto, afirma Adam (2008), mas em cooperação podem inclusive superar falhas e rupturas de uma ou outra em particular. Adam também acredita que os saberes relativos a essas operações são sistemas de conhecimentos linguísticos ativados, quer na produção, quer na interpretação - o que é importante, em nossa opinião, para entender as operações, aqui, não como normas para o "bom texto", mas como recursos que se observam nos textos produzidos pelos falantes e que podem ter diferentes efeitos de ligação entre as proposições-enunciados. A nosso ver, essas operações de ligação, que serviriam de guias ou pistas sobre como interpretar as relações entre os enunciados e cujo efeito pode ser o de uma certa coerência, nunca garantem 
totalmente nem como se interpreta e nem como - ou se - a coerência vai ser estabelecida, mas dependem fundamentalmente de como os interlocutores recebem o texto.

A seguir, alguns exemplos que ilustram cada um dos tipos de ligação, conforme propõe Adam (2008). Observamos que, ainda que a lista de tipos de ligação das unidades textuais de base, conforme a Figura 3, sejam aqui descritas estritamente conforme a proposta do autor, alguns dos exemplos de anáforas e, consequentemente suas análises, são sugestões e adaptações que fizemos 5 . Alertamos também para o fato de que aqui apenas ilustramos algumas categorias de cada grupo, em trechos de textos, sem uma análise muito profunda, apenas para dar uma visão geral de como Adam trata as unidades textuais.

O primeiro tipo de ligação descrito por Adam é o que desempenham as anáforas. Como se sabe, anáfora é um fenômeno em que um referente serve de fonte, para que outras referências a ele possam ser feitas. Essas referências sucessivas vão formando uma rede referencial no texto, estabelecendo relações, e são essenciais para supri-lo de elementos que auxiliam os interlocutores a configurar e a apostar numa unidade semântica.

Exemplo 9: Quis sentar-se num banco do jardim, porque na verdade não sentia a chuva e não se importava com o frio. Só mesmo um pouco de medo, porque ainda não resolvera o caminho a tomar. O banco seria um ponto de repouso. (trecho do conto Fuga, de Clarice Lispector, citado por CIULLA, 2008, p. 49)

Exemplo 10: Ele reconhece ter rodado bêbado(...) O tribunal de correção infligiu ontem uma pena de reclusão ao reincidente. (trecho de sessão de fait divers do jornal suíço La Suisse, adaptado de APOTHÉLOZ E REICHLER-BÉGUELIN, 1999, p. 247)

No exemplo 9, "o banco" retoma o mesmo objeto referido anteriormente por "num banco de jardim". Neste caso, pode-se dizer que é um caso de correferencialidade ${ }^{6}$, já que se trata de um "mesmo objeto"7 que é recuperado.

Ainda que diferente do caso anterior, em que há uma repetição lexical, no exemplo 10, "o reincidente" também recupera correferencialmente um referente já mencionado anteriormente. É interessante observar que, frequentemente, há um acréscimo de informação sobre o referente que é dado não apenas por outras pistas no texto, mas pela própria escolha do termo que designa o referente. Neste caso, sabe-se, por "reincidente", que não era a primeira vez que o indivíduo dirigia bêbado.

Outras situações são também consideradas, em que, de modo diferente dos exemplos anteriores, as anáforas não são correferenciais, mas apontam para a construção de um novo referente, como ilustram os seguintes exemplos:

\footnotetext{
${ }^{5}$ Essas adaptações se devem, por um lado, pelo tamanho dos exemplos de Adam, às vezes muito longos para apresentar num artigo, e, por outro lado, por que a questão da referência anafórica é uma de nossas áreas de especialidade, o que se verifica em diversos trabalhos anteriores, mas principalmente em Ciulla (2008).

${ }^{6}$ Observamos que correferir, aqui, não tem o mesmo sentido do que encontramos em Benveniste, por exemplo, em que esse verbo é utilizado para designar a relação de interlocução entre eu e tu, em que eu toma a palavra e refere, convocando seu alocutário, $t u$, que pode, então, correferir. Não se trata, portanto, da relação de interlocução estabelecida entre as pessoas, na enunciação, mas da relação que se pode estabelecer entre os referentes, num enunciado (num texto).

${ }^{7}$ Os objetos retomados, sob o ponto de vista de Apothéloz e Reichler-Béguelin.
} 
Exemplo 11: Não pegue a xícara amarela. A alça está quebrada. (adaptado de CIULLA, 2008, p. 50)

Exemplo12: No metrô parisiense, há algum tempo, um anúncio publicitário. Vê-se um casal abraçado. Ele a tem em seus braços, deitada. (adaptado de APOTHÉLOZ E REICHLER-BÉGUELIN, 1999, p. 260)

Exemplo 13: Aterrissar na Praça Vermelha! Com certeza, o jovem piloto é maluco... (trecho de sessão de fait divers do jornal suíço La Suisse, adaptado de APOTHÉLOZ E REICHLER-BÉGUELIN, 1999, p. 261)

Exemplo 14: Um gato enorme e branco, que pertence ao jardineiro, saltou no meu colo, e esse safanão fechou o livro que eu havia deixado de lado, para acariciar o animalzinho. (G. De Maupassant, Sur les chats. In: Contes fantastiques. Paris: Marabout, 1992, p. 241)

Nos exemplos de 11 a 14, sem nos determos nos tipos de anáfora, o que importa ressaltar, aqui, são que apresentam a característica de remeter a um referente já mencionado no texto e, ao mesmo tempo, instituir um novo referente no enunciado. No caso de 11 , o referente "a alça" pode ser inferido, pela menção anterior de "xícara", numa aposta de que os interlocutores conhecem as partes que compõem este objeto e, claro, compartilham do léxico que as nomeiam. Em 12, com "ele a tem em seus braços" pressupõe-se que "casal abraçado", mencionado anteriormente, seja formado por uma figura masculina, outra feminina; ao mesmo tempo, "casal" autoriza a inferência sobre "ele/ela" que é mencionada a seguir - isto é, as relações anafóricas não são somente num sentido descendente no texto, mas permitem idas e vindas na leitura e na composição dos referentes. A expressão anafórica "o jovem piloto", em 13, pode ser inferida, pela referência que podemos construir a partir do verbo "aterrissar" e, em 14, é o pulo que o gato dá, acrescido ao fato de que ele seja referido como enorme, que autoriza a menção(e a interpretação) de "esse safanão".

Todos esses casos, aqui apenas analisados en passant, ilustram algumas possibilidades de conexão textual realizadas por anáforas. E embora os exemplos sejam de excertos de textos, é importante lembrar que o papel das anáforas não se restringe às relações de um segmento a outro, mas promovem uma verdadeira teia referencial, que conecta e alcança o texto todo e é, em grande parte, responsável pela própria unidade temática do texto.

Sobre essa permanência tópica, Adam (2008) também recorre a Greimas e sua noção de isotopia:

\begin{abstract}
A existência do discurso - e não de uma sequência de frases independentes - só pode ser afirmada se pode ser postulada, para a totalidade das frases que o constituem, uma isotopia comum, reconhecível, graças a um leque de categorias linguísticas ao longo do seu desenvolvimento. Assim, somos inclinados a pensar que um discurso "lógico" deve ser sustentado por uma rede de anafóricos que, remetendo-se de uma frase a outra, garantem sua permanência tópica. (GREIMAS, 1976, p.28, citado por ADAM, 2008, p. 147)
\end{abstract}

Para ilustrar a análise de isotopias, consideremos brevemente a seguinte análise de um trecho da obra de Jean de la Bruyère, Fragmento 128 de Caracteres, na seção Do Homem:

Exemplo 15: (A) Veem-se certos animais selvagens, machos e fêmeas espalhados pelo campo, negros, lívidos e queimados pelo sol apegados à terra que eles revolvem e [que] esquadrinham 
com uma obstinação invencível; (B) eles têm como que uma voz articulada e, quando eles se erguem sobre os pés, revelam uma face humana; e, de fato, eles são humanos; (C) eles se recolhem, à noite, a covis em que vivem de pão preto, água e raízes: (D) eles poupam os outros homens do trabalho de semear, lavrar e recolher para viver, e merecem, assim, que não lhes falte esse pão que eles semearam. (adaptado de ADAM, 2008, p. 153)

O enunciado (A), marcado por "Veem-se", introduz uma sequência descritiva e indica um ponto de vista, uma percepção. E, por estar em uma seção, cujo título é Do homem, espera-se uma isotopia humana. Contudo, o trecho abre com a proposta de uma isotopia animal: "animais selvagens, machos e fêmeas...". "Revolver" e "obstinação invencível" confirmam, ainda, o que pode ser dito de um animal. É em "apego à terra", talvez, que um sentimento mais humano, de serventia, é introduzido - mas, ainda assim, e somado à aplicação ao trabalho a que a expressão remete, pode manter a isotopia animal. É em (B) que finalmente a isotopia humana é apresentada, com "eles têm como que uma voz articulada...". Além disso, a passagem entre a posição animal, de quatro patas, e a do homo erectus ("eles se erguem sobre os pés") também marca a mudança de isotopia, da animal, para a humana. Como se pode observar, esse fio condutor dado por elementos isotópicos, muitos deles referências anafóricas, auxiliam vigorosamente como elementos de ligação entre os segmentos textuais.

O recurso à colocação também é caro a Adam, pelas relações de ligação que pode estabelecer nos textos. Para o autor, há as colocações em língua, que seriam associações codificadas na língua, pelos lexemas, repertoriados nos dicionários, e as colocações próprias de um texto, que seriam estabelecidas pelas repetições de sequências de lexemas num determinado texto.

Exemplo 16: Era uma vez uma viúva que tinha duas filhas, a mais velha parecia-se tanto com ela, no humor e no rosto, que quem a visse, via a mãe. Elas eram, as duas, tão desagradáveis e tão orgulhosas que não se podia viver com elas. A caçula, que era o verdadeiro retrato do pai, pela doçura e pela honestidade, era, assim, uma das mais belas moças que se podia ver. Como se ama, naturalmente, o seu semelhante, essa mãe era louca pela filha mais velha e, ao mesmo tempo, tinha uma terrível aversão pela mais nova. Ela a fazia comer na cozinha e trabalhar sem parar. Era preciso, entre outras coisas, que essa pobre criança fosse duas vezes ao dia buscar água, a uma grande meia légua de casa, e que a trouxesse numa grande vasilha cheia (...). Assim que essa bela moça chegou em casa, sua mãe a repreendeu por ter voltado tão tarde. Eu lhe peço perdão, disse essa pobre moça (...) A pobre criança contou-lhe, ingenuamente, tudo o que tinha acontecido. (trechos de As Fadas, conto de Perrault, citado por ADAM, 2008, p. 156-157)

Pautando-se pelos eixos nominais que referem a filha caçula ("filha", "criança" e "moça"), Adam pontua que, no conto (não transcrito aqui em sua totalidade), dois adjetivos aparecem em colocação, o de "bela" e o de "pobre". Essas colocações balizam a progressão textual da narrativa, compondo dois espaços: o de "bela" como positivo, que a põe em contato com o pai e suas qualidades, e também com a fada e com o filho do rei, dois personagens que mudarão positivamente seu destino; e o de "pobre", que a põe em contato com a mãe, sempre de modo negativo.

Outros tipos de ligação são os que Adam (2008) atribui às aliterações, rimas, paragramas, anagramas, ritmos e paralelismos gramaticais. Um dos exemplos para os 
paralelismos gramaticais é o do já mencionado discurso de De Gaulle, do exemplo 8. Outro exemplo é o das retomadas fônicas, que, mesmo fora da poesia e dos slogans, podem intervir na prosa, como em "Lyon déroule, Monaco s'écroule" (algo, como "Lyon desponta, Monaco despenca"), que figurava na primeira página de um jornal francês, sobre a vitória do time de futebol Lyon sobre o Monaco. A rima por paronomásia em /e-Rul/ duplica a antítese vencedor vs. perdedor.

Desembaraçando-se de uma visão mais tradicional da elipse, que frequentemente é considerada dentro da noção de uma completude sintática idealizada, Adam mostra exemplos de elipse em pronomes anafóricos, em séries enumerativas, em frases comparativas e em outras situações, mostrando que em todas elas os efeitos formais produzidos permitem jogar com a presença implícita de sentido e com a materialidade rítmica, como nesses versos de Rimbaud:

Exemplo 17: Eu estendi cordas de campanário em campanário; guirlandas de janela em janela; correntes de ouro de estrela em estrela, e eu danço (trecho de Illuminations, de Rimbaud, citado por ADAM, 2008, p. 174)

Também os implícitos (pressupostos e subentendidos) podem desempenhar um papel de ligação entre unidades textuais, pois "a interpretação semântica de um enunciado é o conjunto das consequências ou das conclusões que podem ser inferidas a partir desse enunciado. Numa sequência de proposições, a interpretação de cada uma é inseparável das outras." (ADAM, 2008, p.177) Como prova, o seguinte exemplo:

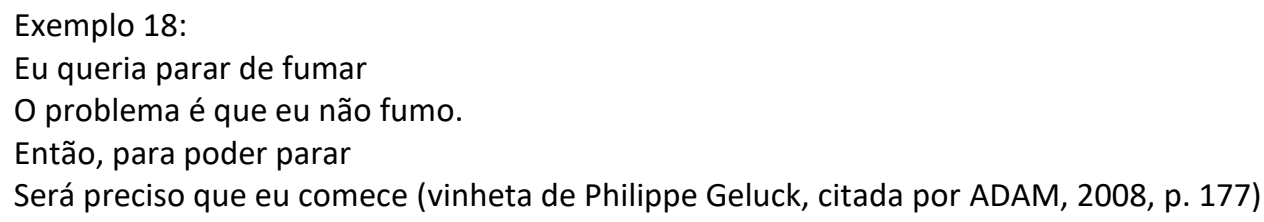

Os conectores são uma classe de expressões que Adam também reagrupa como unidades de ligação. Essa classe reúne algumas conjunções de coordenação já tradicionalmente consideradas na literatura, como mas, portanto, ora, então; também as conjunções e locuções conjuntivas de subordinação, como porque, como, de fato, em consequência, o que quer que seja, então; e grupos nominais ou preposicionais, como apesar disso. Para o autor, é útil classificá-los como conectores argumentativos, marcadores de responsabilidade enunciativa e organizadores e marcadores textuais.

Um exemplo de conector argumentativo é o que segue:

Exemplo 19: FUTEBOL. O internacional Michael Owen (24 anos/Liverpool) vai assinar com o Real Madrid. As modalidades de transferência não são conhecidas. NO ENTANTO, o francês Patrick Vieira não vestirá a camisa branca do Real Madrid. Ele anunciou que permanecia fiel ao Arsenal. (Agence France-Presse, citado por Adam, 2008, p. 185)

Adam observa que o marcador de oposição "no entanto", acima, assinala tanto a mudança de objeto do discurso quanto a oposição da situação dos dois jogadores. 
Para os marcadores de responsabilidade enunciativa, um dos exemplos de Adam é:

Exemplo 20: Robin e Cugnein foram encontrados feridos em Versailles (p1). Vítimas de agressão, dizem eles (p2). Duelistas com faca, acredita-se (p3). (trecho de um fait divers de Félix Fénéon, citado por ADAM, 2008, p. 187)

O fato descrito p1, em 20, é interpretado a partir de dois pontos de vista divergentes: o dos protagonistas, em p2, e o do jornal ou da polícia, em p3, sem que fique claro se o locutor se inclui ou não na afirmação de "acredita-se".

Os organizadores textuais podem ser, ainda, espaciais, temporais ou enumerativos:

Exemplo 21: Havíamos procurado um confeiteiro em Yverot para as tortas e docinhos. Como ele era recém-chegado se iniciando no país, havia cuidado das coisas: e trouxera, ele mesmo, de sobremesa, um bolo confeitado que provocou exclamações. NA BASE, PRIMEIRO, havia uma fileira de papelão azul, com o formato de um templo com pórticos, colunas e estatuetas feitos de confeito marmorizado, ao redor de fartas constelações de estrelas em papel dourado. A SEGUIR, NO SEGUNDO ANDAR, uma masmorra de bolo de Savoia, rodeado de pequenas fortificações de caules de flor de angélica açucarados, amêndoas, uvas-passas e gomos de laranjas; E ENFIM, SOBRE A PLATAFORMA SUPERIOR, que era uma pradaria verde, onde havia rochedos com lagos de doce de frutas e barcos de cascas de avelãs, via-se um pequeno "Amor", balançando-se em uma plaqueta de chocolate, cujas duas hastes de sustento eram adornadas por dois botões de rosa natural, em formato de esfera, no topo. (trecho de Madame Bovary, de Gustave Flaubert, citado por ADAM, 2019, p. 44)

A ordem espacial imposta pelo plano do texto indica uma lógica de fabricação, que baliza a leitura, conduzindo o leitor a construir a imagem do bolo, sempre acompanhando a progressão induzida pelos marcadores (em caixa alta, no exemplo): "na base, primeiro...", "a seguir, no segundo andar...", e assim por diante.

Quanto aos marcadores textuais, Adam (2008) salienta que sua importância é muitas vezes negligenciada, em especial a de marcadores de ilustração e de exemplificação, como é caso de por exemplo, notadamente, em particular, entre outros e assim. No entanto, sua função é indicar o status da ilustração ou do exemplo como asserção principal, como podemos ver, a seguir.

Exemplo 22: O Pajero corresponde às exigências de cada um! Por exemplo, o Pajero Metal: primeiramente um sistema de transmissão super select, único, que integra os recursos de tração permanente aos da tração com engate. (publicidade de automóvel, citado por ADAM, 2019, p. 44)

Por fim, ainda sobre os operadores de ligação entre segmentos textuais, Adam (2008) argumenta que um texto não é uma simples sequência de atos de enunciação que possui um certo valor ilocucionário, mas é uma estrutura de atos de discurso ligados entre si. Fundamentando-se em Vanderveken (1992), Adam (2008) afirma que no uso da linguagem, são os atos ilocucionário completos, e não as proposições isoladas, que são as unidades de base da significação. O exemplo dado para descrever as operações de ligação realizadas por atos de discurso é 
Exemplo 23: (A1) Bravo! Vejo que, (A2) apesar do que se schtroumpfou, (A3) vocês permaneceram bons e corajosos schtroumpfinhos! (A4) Vamos, eu os perdôo! (trecho de vinheta do cartunista Peyo, citada por ADAM, 2008, p. 197)

$\mathrm{Na}$ interpretação de Adam, esta é uma sequência de atos de discurso que precisa ser analisada em seu conjunto, para compreender esse trecho, que é a réplica de um personagem. Adam procede a uma detalhada decomposição em 4 atos de discurso (marcados por A, no exemplo). Contudo o que destacamos é a sua argumentação de que os atos sucessivos não são simplesmente justapostos, mas ligados entre si, de tal maneira, que os dois atos de discurso assertivos-constativos A2 e A3 são ligados por um ato englobante de concessão, marcado por "apesar de"; além disso, a essa estrutura juntam-se, em uma ponta, o ato expressivo $A 1$, que incide sobre $A 3$, e, na outra ponta, o ato declarativo $A 4$, que assume a forma de performativo explícito e, por ter sido permitido por $A 3$, incide retrospectivamente em A2. A proposição marcada por "apesar de" é um argumento para uma conclusão negativa, no entanto, o argumento de A3 domina e possibilita o fechamento de A4. Assim, ilustramos o que Adam chama de estrutura hierárquica de atos, que funcionam como operadores de ligação de segmentos textuais.

A seguir, alguns comentários sobre a abordagem, em geral, de texto, em Adam, que considera a estrutura composicional dos textos e sua consequente classificação.

\section{Tipo e prototipia}

A grande questão de Adam diz respeito à estrutura composicional dos textos. Para o autor há um número bastante limitado de sequências textuais de base, que são os tipos monogeridos narrativo, descritivo, argumentativo e explicativo e o poligerido dialogal. Seu objetivo, para este aspecto, é descrever o fato de os textos apresentarem uma composição de fragmentos de muitos tipos mais ou menos articulados entre si, como é o caso da presença da descrição na narrativa, de narração na explicação, de explicação na argumentação, etc.

Outro conceito importante, desenvolvido mais recentemente, é o da prototipia. Para Adam (2019, p.6) trata-se de um "esquema ou imagem mental do protótipo abstrato, construído a partir de propriedades típicas da categoria que permite o reconhecimento subsequente deste ou daquele exemplo como mais ou menos prototípico." (ADAM, 2019, p. 63). Isso significa que a realização de uma sequência está dentro de um modelo mais ou menos esperado, que foi reconhecido em textos anteriores, mas não tem em vista excluir os demais exemplares que estejam, de algum forma, fora do que é esperado. A proposta é a de englobar mais realizações dentro daquilo que se vai constantemente construindo como um protótipo, a partir da ilimitada capacidade criativa dos sujeitos na linguagem.

O conceito de tipos de textos, na prudente opinião de Adam (2019) está mais para um obstáculo metodológico do que para uma ferramenta heurística. $O$ autor demonstra, com esta afirmação, que tem ciência dos problemas que as classificações acarretam, especialmente quando se trata de classificar produtos simbólicos de práticas discursivas humanas. Contudo, citando Gilbert Dispaux (1984, p.102), justifica-se: "uma definição que não tivesse jamais 
provocado questionamento seria inútil. O mesmo vale para uma tipologia". Assim, Adam não pretende oferecer um modelo completo, muito menos normativo, para uma análise de textos, mas, sim, como já foi dito anteriormente, tem o intuito de fornecer instrumentos que ajudem na compreensão das produções discursivas humanas a partir de uma certa noção de texto.

\section{Considerações finais}

Neste percurso que apresentamos, o objetivo foi o de pontuar as questões problemáticas de base para uma linguística que pretende ter o texto como centro de seus estudos. Para isso, mostramos como Adam faz voltar a reflexão de Benveniste sobre os problemas da linguagem que escapam às explicações mais sistemáticas que podem ser dadas à gramática e ao léxico, mas não dão conta daquilo que acontece quando se trata de textos. Daí a constatação fundamental de que no texto as relações do todo com a parte não obedecem ao mesmo tipo de previsibilidade da frase e seus constituintes e, por isso, é necessário constituir uma nova abordagem linguística.

Percebe-se em Adam, desde o início, o movimento de identificar o salto que é dado entre uma linguística da língua e uma linguística do discurso, para encontrar o lugar do texto. E para apontar um caminho que assegura este salto, retorna a Benveniste, fundamentando, assim, a sua proposta para a linguística textual.

Vê-se que a história da origem de uma linguística que dê conta da língua em funcionamento, ou seja, do âmbito discursivo da linguagem, confunde-se com a história da linguística textual.

Salientamos, por fim, que, diferentemente de outras abordagens de análises textuais, Adam não toma simplesmente as categorias sugeridas por Benveniste, mas parte da sua reflexão teórica e metodológica para repensar o texto e propor a sua análise textual dos discursos, a partir de categorias próprias para o texto e concomitantemente condizentes com uma teoria enunciativa da linguagem.

\section{Referências}

ADAM, Jean-Michel. La linguistique textuelle. Introduction à l'analyse textuelle des discours. Armand Colin: Paris, 2005.

ADAM, Jean-Michel. A linguística textual. Introdução à análise textual dos discursos. Tradução da 2a edição, revisada e ampliada. Maria das Graças Soares Rodrigues, Luís Passeggi, João Gomes da Silva Neto e Eulália Leurquin. São Paulo: Cortez Editora, 2008.

ADAM, Jean-Michel. Le programme de la "translinguistique des textes, des oeuvres" e sa réception au seuil des années 1970. In : BRUNET, Emilie; MAHRER, Rudolf. Relire Benveniste : réceptions actuelles de Problèmes de linguistique générale (org.) Paris : I'Harmattan, 2011. p. 123-147. 
ADAM, Jean-Michel. Pratiques, la linguistique textuelle et l'analyse du discours, dans le contexte des années 70. Pratiques, número especial Enseignement/apprentissage de la langue, des textes et des discours, p. 169-170, 2016. https://doi.org/10.4000/pratiques.2931

ADAM, Jean-Michel. Textos: tipos e protótipos. Tradução de Mônica Cavalcante, Alena Ciulla, Valdinar Custódio Filho e outros. São Paulo: Editora contexto, 2019.

APOTHÉLOZ, Denis; REICHLER-BÉGUELIN, Marie-José. Interpretations and functions of demonstrative NPs in indirect anaphora. Journal of Pragmatics, v. 31, n. 3, p. 363-397, mar. 1999. https://doi.org/10.1016/S0378-2166(98)00073-3

BELLERT, Irena. On a condition of the coherence of texts. Sémiotique, v. 2, n. 4, 1970 p. 335363. https://doi.org/10.1515/semi.1970.2.4.335

BENVENISTE, Émile. Problèmes de linguistique générale, 1. Paris: Gallimard, 1966.

BENVENISTE, Émile. Problèmes de linguistique générale, 2. Paris: Gallimard, 1974.

BERRENDONNER, Alain. Les deux syntaxes. In: CHAROLLES, Michel, LE GOFFIC, Pierre e MOREL, Mary-Annick (orgs.) Verbum. Nancy : Presses Universitaires de Nancy, v. XXIV, n.1-2, 2002, p. 23-35.

BÜHLER, Karl. Sprachtheorie: Die Darstellungsfunktion der Sprache. Jena: Fischer, 1934.

CHAROLLES, Michel. Analyse de discours, grammaire de texte et approche grammaticale des faits de textualité. Le Français aujourd'hui, n. 86, 1989, p. 6-16.

CHAROLLES, Michel. Les plans d'organisation du discours et leurs interactions. In : S. Moirand et al. (orgs.) Parcours linguistiques de discours spécialisés. Berne : Peter Lang, 1993, p. 301314.

CIULLA, Alena. Os processos de referência e suas funções discursivas: o universo literário dos contos. 201f. Tese (Doutorado em Linguística). Universidade Federal do Ceará, Fortaleza, 2008.

COMBETTES, Bernard. Questions de méthode et de contenu en linguistique du texte. Études de linguistique appliquée. Paris: Didier, n.87, p.107-116, 1992.

COSERIU, Eugenio. Sistema, norma e fala. Revista de la Faculdad de Humanidade y Ciencias, Montevideo, ano VI, n. 9, p.113-191, 1952.

COSERIU, Eugenio. Lingüística del texto, Introdución a la hermenêutica del sentido, edição e anotação de Oscar Loureda Lamas. Madrid: Arco/Libros, [1980] 2007.

CULIOLI, Antoine. Préface. In : ATLANI, Françoise et al. La langue au ras du texte. Lille : Presses Universitaires de Lille, 1984. p. 9-12.

DISPAUX, Gilbert. La Logique et le cotidien. Paris : Minuit, 1984.

HUMBOLDT, Wilhem von. Gesammelte Schriften. Berlim: A.Leitzmann, Behr, 1903-1936, 17 v.

PRANDI, Michele. Les fondements méthodologiques d'une grammaire descriptive de l'italien. Langages. Paris, Larousse, n.167, 2007, p.70-84. https://doi.org/10.3917/lang.167.0070

RASTIER, François. Sens et textualité. Paris : Hachette, 1989. 
RUWET, Nicolas. "Parallélismes et déviations en poésie ». In : Kristeva, J., Milner, J.-C. \& Ruwet, N. (dirs), Langue, discours, société. Pour Émile Benveniste. Paris : Seuil, 1975, p. 307351.

SAUSSURE, Ferdinand de. Curso de linguística geral. São Paulo: Cultrix, 1974.

VANDERVEKEN, Daniel. La théorie des actes de discours et l'analyse de la conversation. Cahiers de linguistique française. Genève : Université de Genève, n. 13, 1992. p. 9-61.

Recebido em: 24/10/2019.

Aceito em: 09/03/2020. 